\title{
Knowledge and practices of visual acuity screening by primary school educators
}

Authors:
Yentl M. Juggernath ${ }^{1}$
Stephen E. Knight ${ }^{1}$
Affiliations:
1Discipline of Public Health
Medicine, University of
KwaZulu-Natal, South Africa
Correspondence to:
Yentl Juggernath
Email:
yentlmj@gmail.com
Postal address:
20 Daydawn Close,
Kharwastan, Chatsworth
4092, South Africa
Dates:
Received: 18 Apr. 2015
Accepted: 24 Aug. 2015
Published: 18 Nov. 2015
licensed under the Creative
How to cite this article:
Juggernath YM, Knight SE.
Knowledge and practices of
visual acuity screening by
primary school educators.
Afr Vision Eye Health.
2015;74(1), Art. \#309,
5 pages. http://dx.doi/
org/10.4102/aveh.v74i1.309

Background: The World Health Organization estimates that 12 million children worldwide between the ages of 5 and 15 years have visual impairment owing to uncorrected refractive error.

Aim: To assess whether the knowledge and practices of visual acuity (VA) screening improved after structured training of Grade 5 educators.

Setting: Primary schools in Chatsworth, a suburb of Durban, South Africa.

Method: A cluster randomised controlled trial was conducted. Bioethics approval and informed consent was obtained. Thirty-eight of 41 schools were randomised to an intervention or control group. Each Grade 5 classroom was given a Snellen chart, and educators from the intervention schools received structured training on VA screening and how to recognise visual impairment in learners. Data were collected from the 19 intervention and 18 control educators using a self-administered questionnaire at outset (baseline) and 6 weeks later in both groups. The Wilcoxon signed-rank test was used to measure the significance of changes.

Results: The proportion of trained primary school educators who had adequate knowledge of VA screening increased significantly from 5.3\% to $100 \%$ in the intervention group. In the control group, educators' knowledge of VA screening stayed the same. The proportion of trained educators who performed VA screening of children increased from $0 \%$ to $79 \%(p<0.001)$.

Conclusion: A simple structured VA screening programme presented to primary school educators increased their knowledge and led to improved visual screening practices in the classroom.

\section{Introduction}

The World Health Organization (WHO) estimates that 285 million people worldwide have visual impairment owing to uncorrected refractive error. Twelve million are children between the ages of 5 and 15 years with refractive errors, which could easily be diagnosed with appropriate visual acuity (VA) screening and then corrected. Myopia is the cause of $90 \%-95 \%$ of visual impairment among children in this age range and makes many daily activities difficult, including reading from the blackboard in school, which can affect a child's academic performance. ${ }^{1}$ Approximately $90 \%$ of the world's visually impaired live in low- and middle-income countries (LMICs), and $80 \%$ of all visual impairment can be either avoided or corrected. ${ }^{1}$ In Durban, South Africa, 4890 black youths between the ages of 5 and 15 years underwent VA acuity screening in 2002. The prevalence of uncorrected, presenting and best-corrected VA of 6/12 or worse in the better eye was $1.4 \%, 1.2 \%$ and $0.3 \%$ respectively. There were 191 eyes with decreased vision, and $63 \%$ were because of refractive error. ${ }^{2}$

Reduced VA can prevent children from achieving their full potential. Children with refractive error have double the risk of academic failure, which can lead to dropping out of school, reduced access to tertiary education, poorer occupation prospects and lower socioeconomic status, with eventual loss of economic productivity., Early detection of visual impairment is essential to optimising learning and academic development. ${ }^{1}$

A related concern is the uneven distribution of optometrists in low- and high-income countries, and in urban and rural areas. In most upper- and middle-income countries, the optometrist-topopulation ratio is approximately 1:10 000. ${ }^{5}$ In South Africa (SA), most optometrists work in the privately funded healthcare sector. Only $16 \%$ (8.1 million) of the population have healthcare cover (insurance) from private medical aids and are able to obtain eye care in the areas where most optometrists practise. ${ }^{6}$ The rest of the population have to rely on the public sector for optometric care, where one fulltime optometrist per 543000 of the population means that services to most of the population are inaccessible. ${ }^{7}$ 
Education is compulsory for children aged 7-15 years in South Africa. In 2010, there were 11 million children in SA between the ages of 7 and 17, of whom 10.8 million (98\%) were attending school. ${ }^{8}$ Schools are a convenient environment for VA screening. Educators spend approximately 25 hours per week with a classroom of children, and are in a good position to identify vision problems in children.

The goal of the WHO's Global School Health Initiative is to increase the number of schools that improve children's health. ${ }^{9}$ A health-promoting school is 'a school constantly strengthening its capacity as a healthy setting for living, learning and working'. Health and education officials, teachers, students, parents, health providers and community leaders all have a role to play in making the school a healthy place for children. The WHO in collaboration with Vision 2020 aims to eliminate uncorrected refractive error. Their strategies include improving public awareness by community-based initiatives and school-based eye health programmes.

VA screening involves assessing the child's ability to see the smallest letters on a standardised Snellen chart held at $6 \mathrm{~m} .{ }^{10}$ The test can be conducted in a healthcare practice, a school, a workplace and elsewhere. Studies in some middleincome countries have demonstrated that the classroom is an appropriate environment for VA screening of children. ${ }^{11}$ In LMICs, if resources are available, it is ideal for learners to be screened between the ages of 6 and 11 years, and then between 12 and 14 years, which are the ages when myopia begins and progresses. ${ }^{5}$ Grade 5 learners have sufficient intellectual and cognitive ability to understand VA screening performed in a non-clinical setting.

In Tanzania, educators were taught how to perform VA screening using a Snellen Tumbling E chart at $6 \mathrm{~m}$ as well as to ask learners questions related to reduced vision. ${ }^{12}$ The screening was successfully performed by randomly selected educators on rural primary school learners between 7 and 19 years old, and later confirmed by ophthalmic professionals. The prevalence of uncorrected VA in 1386 learners was $0.7 \%$. The sensitivity and specificity for the educators' VA screening and screening questions were $80 \%$ and $91 \%$ respectively.

In Delhi, a VA screening education intervention for primary school teachers resulted in significantly improving their knowledge of eye function and common childhood eye diseases. With this knowledge, educators were able to dispel local myths concerning visual impairment and provide sustainable eyecare awareness for learners. Educators are respected in communities and have a role as health awareness ambassadors after appropriate training. ${ }^{11}$

The aim of the present study was to assess whether the knowledge and practice of VA screening amongst Grade 5 educators could be extended with the introduction of a structured training programme.

\section{Research methods and design Study design}

A cluster randomised controlled trial, with a parallel group design and an allocation ratio of 1:1 was conducted.

\section{Setting}

The study was conducted in primary schools in the suburb of Chatsworth, in Durban, South Africa.

\section{Study population and sampling strategy}

The study population comprised Grade 5 educators in the 41 public-funded primary schools in Chatsworth. A multi-stage sampling strategy was used. A simple random sample of 38 schools was selected and these schools were randomised to 19 intervention and 19 control schools. Only 29 of the school principals (15 in the intervention group and 14 in the control group) granted 'gate-keeper' permission for their schools to participate in the study. Insufficient time available was the reason given by principals for refusing educators to participate in the study. If a school had one or two Grade 5 educators, one educator was randomly selected; and if a school had three or more Grade 5 educators, two educators were randomly selected per school. Thirty-seven educators (19 in the intervention group and 18 in the control group) were selected and agreed to participate in the study.

\section{Intervention}

A Snellen chart was introduced into Grade 5 classrooms in all the study schools. Educators in the intervention group underwent simple but structured training on how to recognise children with visual impairment and to conduct standardised VA screening using a Snellen chart (Figure 1). The control group educators received no training.

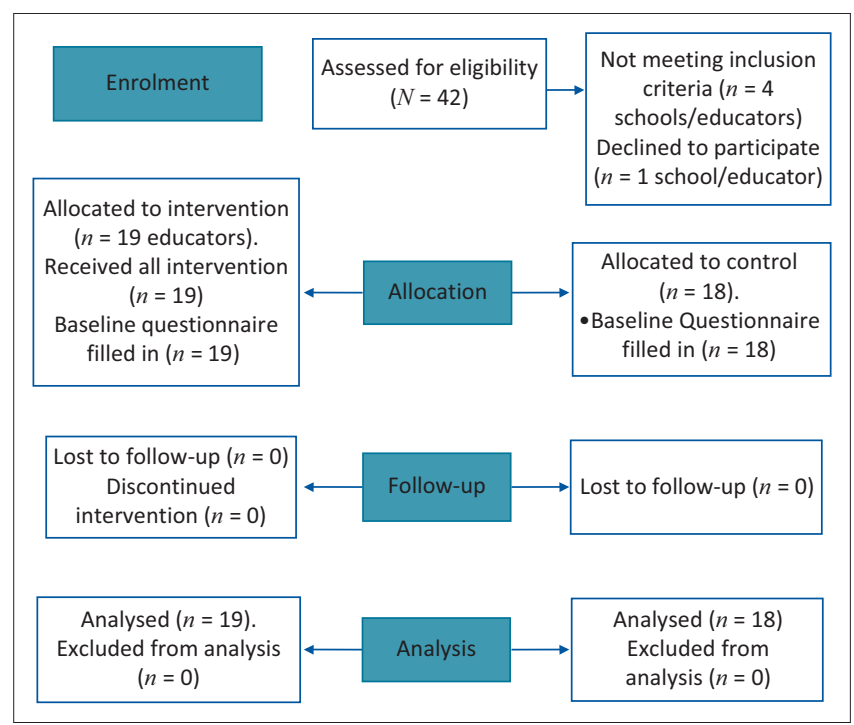

Source: Principal author

FIGURE 1: Flow diagram of visual acuity screening by Grade 5 educators in Chatsworth primary schools in 2013. 


\section{Data collection}

Data were collected using the same standardised, anonymised and self-administered questionnaires in the control and intervention groups at baseline and after 6 weeks. The questionnaire included some demographic data about the educators, their understanding and previous training in ocular health, and current knowledge and practices of VA screening and its correction.

\section{Data analysis}

Nominal and categorical data were captured and analysed using the Statistical Package for Social Sciences (SPSS), version 21. Frequencies for demographic variables, current knowledge and practices, behaviour and beliefs were calculated. The results from pre- and post-intervention were compared using the Wilcoxon signed-rank test. $P$-values $<0.05$ were considered statistically significant.

\section{Ethical considerations and permission}

Ethical approval for the study was granted by the Biomedical Research Ethics Committee of the University of KwaZuluNatal (BE301/12). The KwaZulu-Natal Department of Education gave permission for educators' schools to participate in the study if the school principals agreed. Consent forms were explained verbally and signed by educators prior to commencement of the study. An information sheet was handed out to each participant, who did not know whether they were in the intervention or control group prior to signing consent forms, thus ensuring concealment of randomisation.

\section{Results}

The baseline characteristics and ocular history between the intervention and control groups of educators in this randomised controlled trial were very similar regarding gender, education level and the educators' own experience of vision screening and correction (Table 1).

Pre-intervention, $84 \%$ of both educators in the intervention and control groups thought that educators could play a role in the VA screening of learners, which increased in both groups to $95 \%$ and $96 \%$ after 6 weeks respectively (Table 2). Knowledge of the benefits of VA screening improved in both the intervention and control groups but these changes were

TABLE 1: Characteristics and ocular history of Grade 5 educators in Chatsworth primary schools in 2013.

\begin{tabular}{|c|c|c|c|c|}
\hline \multirow[t]{2}{*}{ Characteristics } & \multicolumn{2}{|c|}{ Intervention $\dagger$} & \multicolumn{2}{|c|}{ Control: } \\
\hline & $n$ & $\%$ & $n$ & $\%$ \\
\hline \multicolumn{5}{|l|}{ Gender } \\
\hline Female & 15 & 79 & 14 & 78 \\
\hline \multicolumn{5}{|l|}{ Age } \\
\hline Mean age (s.d.) (years) & 46.7 & 11 & 45 & 9.7 \\
\hline Range & $23-67$ years & - & $21-59$ years & - \\
\hline \multicolumn{5}{|l|}{ Years of service } \\
\hline Mean (s.d.) & 22.1 & 10 & 30 & 8.9 \\
\hline Range & $2-38$ years & - & $1-33$ years & - \\
\hline \multicolumn{5}{|c|}{ Highest level of education } \\
\hline Diploma & 5 & 26 & 3 & 17 \\
\hline Degree & 14 & 74 & 15 & 83 \\
\hline Had vision test & 17 & 90 & 18 & 100 \\
\hline Wear correction§ & 12 & 63 & 11 & 61 \\
\hline
\end{tabular}

TABLE 2: Outcomes of the intervention and control group for knowledge and practices of visual acuity screening of Grade 5 educators in Chatsworth primary schools in 2013.

\begin{tabular}{|c|c|c|c|c|c|c|c|c|c|c|}
\hline \multirow[t]{3}{*}{ Testing outcomes } & \multicolumn{4}{|c|}{ Intervention group $n=19$} & \multirow[t]{3}{*}{$p$ value } & \multicolumn{4}{|c|}{ Control group $n=18$} & \multirow[t]{3}{*}{$p$ value } \\
\hline & \multicolumn{2}{|c|}{ Pre-intervention } & \multicolumn{2}{|c|}{ Post-intervention } & & \multicolumn{2}{|c|}{ Pre-intervention } & \multicolumn{2}{|c|}{ Post-intervention } & \\
\hline & $n$ & $\%$ & $n$ & $\%$ & & $n$ & $\%$ & $n$ & $\%$ & \\
\hline \multicolumn{11}{|l|}{ Benefits of VA testing } \\
\hline Increased detection & 17 & 90 & 18 & 95 & 0.08 & 15 & 83 & 16 & 89 & 0.32 \\
\hline Provides a tool for screening & 1 & 5.3 & 18 & 95 & $<0.01$ & 10 & 56 & 14 & 79 & 0.07 \\
\hline Increased awareness and early detection & 11 & 58 & 18 & 95 & 0.86 & 5 & 28 & 5 & 28 & 0.91 \\
\hline \multicolumn{11}{|l|}{ Trained in VA screening } \\
\hline Method & 1 & 5.3 & 19 & 100 & $<0.01$ & 0 & 0 & 0 & 0 & 1 \\
\hline Instruction & 0 & 0 & 19 & 100 & $<0.01$ & 0 & 0 & 0 & 0 & 1 \\
\hline Test distance & 1 & 5.3 & 19 & 100 & $<0.01$ & 0 & 0 & 0 & 0 & 1 \\
\hline Recording & 0 & 0 & 19 & 100 & $<0.01$ & 0 & 0 & 0 & 0 & 1 \\
\hline Aware of eye signs and symptoms & 12 & 63 & 18 & 95 & $<0.01$ & 8 & 44 & 8 & 44 & 1 \\
\hline Peering & 5 & 26 & 17 & 90 & $<0.01$ & 4 & 22 & 5 & 28 & 0.56 \\
\hline Copying from board & 7 & 37 & 13 & 69 & 0.13 & 6 & 33 & 7 & 39 & 0.32 \\
\hline Headaches & 1 & 5 & 7 & 37 & 0.16 & 0 & 0 & 0 & 0 & 1 \\
\hline Head tilt & 1 & 5 & 9 & 48 & 0.31 & 0 & 0 & 0 & 0 & 1 \\
\hline Poor performance at school & 4 & 21 & 14 & 73 & 0.62 & 3 & 17 & 4 & 22 & 0.56 \\
\hline Complains of poor vision & 2 & 11 & 13 & 68 & 0.8 & 1 & 5.6 & 1 & 5.6 & 1 \\
\hline School policy & 1 & 5.3 & 2 & 11 & 0.56 & 3 & 17 & 3 & 17 & 1 \\
\hline Move learner closer to the board & 1 & 5.3 & 1 & 5.3 & 0.41 & 0 & 0 & 0 & 0 & 1 \\
\hline Letter to parent & 0 & 0 & 1 & 5.3 & 0.79 & 1 & 5.6 & 0 & 0 & 0.32 \\
\hline Refer to health professional & 0 & 0 & 1 & 5.3 & 0.79 & 2 & 11 & 3 & 17 & 0.32 \\
\hline \multicolumn{11}{|l|}{ Practice } \\
\hline Test with Snellen chart & 0 & 0 & 15 & 79 & $<0.01$ & 0 & 0 & 0 & 0 & 1 \\
\hline Refer appropriately & 0 & 0 & 14 & 73 & $<0.01$ & 0 & 0 & 0 & 0 & 1 \\
\hline
\end{tabular}


not significant in either group. The understanding of how the Snellen chart provides a tool for educators to perform VA screening showed a significant improvement in the intervention group (Table 2).

Neither group had been trained in VA screening at baseline, although one educator in the intervention group had some knowledge of VA screening, but demonstrated an incorrect technique. After the intervention, all the trained educators could describe the VA screening method, set up the Snellen chart, instruct the learners correctly and record the learners' VA using a Snellen chart. None of the control group educators said that they could conduct VA screening correctly at baseline or after 6 weeks.

The number of educators with correct knowledge of signs and symptoms linked to poor vision increased from 12 to 18 post-intervention. Eight of the control educators knew the signs and symptoms that a learner with reduced vision would present with at baseline, after 6 weeks.

Knowledge of school policy on how to assist learners with visual impairment did not change in the intervention or control group significantly.

Educators were also asked if they had performed VA screening on learners. In the control group, none of the educators reported having detected or referred learners with reduced vision. After the intervention, 15 of the trained educators screened 300 learners for VA using the Snellen chart.

\section{Discussion}

In the present randomised clinical trial, there was no significant difference in the baseline characteristics in the intervention and control groups. The outcome of the study was very likely the result of the intervention.

There were more female educators in the study, which reflects the situation in South Africa, where $71 \%$ of educators are women. ${ }^{13}$ As there are generally more female than male educators, any initiative in LMICs is likely to be based on women educators, and therefore the results of the present study could be generalisable to other areas.

Prior to the intervention, the baseline knowledge about VA screening was low and none of the educators had been trained. Educators' baseline knowledge of learners' eye health was also found to be limited in a study conducted in a junior school in India. ${ }^{5}$ After training, educators were more knowledgeable about signs and symptoms that a learner with reduced vision would present with. This finding was similar to a study in Nigeria where educators' knowledge of signs and symptoms improved after training. ${ }^{14}$

After their training on VA screening, all educators retained the knowledge and VA screening skills conveyed. Studies conducted in Tanzania and Mozambique also showed that, after structured VA training, all educators retained the screening skills. ${ }^{12,15}$ The majority (79\%) of trained educators used their knowledge and skills in VA screening to screen learners for visual impairment. The educators who did not screen learners were from the last four schools where educators were trained. The timing of the intervention was too late in the year for these educators to conduct screening, as they were engaged in end-of-year examinations. In India, $92 \%$ of educators who had volunteered for training conducted VA screening of their class within 10 days of being trained. ${ }^{11}$ In our study, we had a very positive response despite the educators being randomly selected for participation.

Very few educators were aware of the presence of a school policy on managing visual impairment of learners. The structured training did not emphasise the importance of having a school policy. The Department of Basic Education in SA introduced The Integrated School Health Policy of 2012 which includes information for educators on how to manage learners with visual impairments, the importance of VA screening, the presenting signs and symptoms of reduced VA in learners, common vision disorders, and what can be done to correct or manage visual problems. ${ }^{16}$ None of the educators mentioned that they were aware of this policy or the standard messages.

\section{Strengths and limitations}

The present randomised controlled trial was designed according to the Consort Statement principles. ${ }^{17}$ The sample size was smaller than originally planned. Despite permission from the Education Department, some school principals refused 'gate-keeper' permission for the study to be conducted in their schools. Mostly, there was only one educator per school who met the inclusion criteria for the study. There was no loss to follow-up which meant that educators in both arms of the trial who agreed to participate, completed questionnaires at baseline and six weeks later. Masking (blinding) seeks to prevent performance and ascertainment bias; it protects the sequence after allocation. ${ }^{18}$ Masking was not performed in the present study because both the researcher and the participants were aware that the intervention was being performed or not.

Information bias was reduced as the researcher conducted all steps of this small study because there were limited funds to employ field workers. A pilot study was conducted to ensure that the questions were concise, unambiguous and understandable.

Binary logistic regression was used to determine if confounding factors had an effect on the outcome. The confounders included age, gender, years of service, education level, previous eye examinations and use of spectacles or contact lenses. There was no significance $(p<0.01)$ between the confounders and the outcome of the study.

\section{Conclusion}

Educators can be trained effectively about reduced VA of learners and how to perform VA screening using clinical signs and symptoms and a standardised Snellen chart in 
a classroom setting. The Integrated School Health Policy describes the role that educators should play to eliminate uncorrected refractive error. A simple structured programme on VA screening should be initiated to provide educators with the knowledge and skills to perform VA screening on learners in the classroom environment.

\section{Acknowledgements Competing interests}

Funding was awarded to the researcher by the College of Health Science, University of KwaZulu-Natal. The funder had no role in the development of the study design, data collection and analysis, and the preparation of this article.

\section{Authors' contributions}

Y.M.J. (University of KwaZulu-Natal) was the principal investigator, and responsible for the study design, data collection, intervention and writing of the article. S.E.K. (University of KwaZulu-Natal) was the Master of Public Health research study supervisor, and responsible for conceptual contributions and editing of the article.

\section{References}

1. Pascolini D, Mariotti SP. Global estimates of visual impairment: $2010 . \mathrm{Br}$ Ophthalmol. 2012:96:614-618. PMID: 22133988, http://dx.doi.org/10.1136/ bjophthalmol-2011-300539

2. Naidoo KS, Raghunandan $A$, Mashige $K P$, et al. Refractive error and visual impairment in African children in South Africa. Invest Ophthalmol Vis Sci. 2003;44:3764-3770. PMID: 12939289, http://dx.doi.org/10.1167/iovs.03-0283

3. Smith TS, Frick KD, Holden BA, Fricke TR, Naidoo KS. Potential lost productivity resulting from the global burden of uncorrected refractive error. Bull World Health Org. 2009;87:431-437. PMID: 19565121
4. Ayed T, Sokkah M, Charfi O, El Matri L. Epidemiological study of refractive errors in school children in socioeconomically deprived regions in Tunisia. J Fr Ophthalmol. 2002;25:712-717. PMID: 12399727

5. Holden BA. The role of optometry in Vision 2020. Community Eye Health. 2002;15:33-36. PMID: 17491876

6. Statistics South Africa. Use of health facilities and levels of selected health conditions in South Africa: Findings from the General Household Survey 2011. c2013 [cited 2015 Jan 20]. Available from: http://www.statssa.gov.za/ publications/Report-03-00-05/Report-03-00-052011.pdf

7. Department of Health. Human resource strategy for the health sector $2012 / 13-$ 2016/17. c2012 [cited 2015 Jan 20]. Available from: http://www.doh.gov.za/docs/ stratdocs/2012/hrhstrat.pdf

8. Department of Basic Education. Education statistics in South Africa 2011. c2013 [cited 2014 June 06]. Available from: http://www.education.gov.za/EMIS/ StatisticalPublications/tabid/462/Default.aspx

9. World Health Organization. Improving health through schools: National and international strategies. c1999 [cited 2014 Aug 08]. Available from: http://www. who.int/school_youth_health/media/en/94.pdf

10. MedlinePlus. Visual acuity test. c2014 [cited 2014 Aug 08]. Available from: http:// www.nlm.nih.gov/medlineplus/ency/article/003396.htm

11. Datta CA, Bhardwaj LN. Study of disorders of visual acuity amongst adolescent school children in Pune. MJAFI. 2009;65:26-29.

12. Wedner SH, Ross DA, Balira R, Kaji L, Foster A. Prevalence of eye diseases in primary school children in rural area of Tanzania. Br J Ophthalmol. 2000;84:12911297. PMID: 11049957, http://dx.doi.org/10.1136/bjo.84.11.1291

13. Department of Basic Education. Education statistics in South Africa 2012. c2014 [cited 2014 Aug 08]. Available from: http://www.education.gov.za/LinkClick.aspx? fileticket $=\% 2 \mathrm{FxGqk} \% 2 \mathrm{~F} 1 \mathrm{E} 2 \mathrm{IY} \% 3 \mathrm{D} \&$ tabid $=36 \& \mathrm{mid}=2514$

14. Tabansi PN, Anochie IC, Nkanginieme KEO, Pedro-Egbe CN. Evaluation of teachers' performance of vision screening in primary school children in Port Harcourt. AJOL. 2009;17 [cited 2014 Aug 20]. Available from: http://www.ajol.info/index.php/njo/ article/view/46759

15. Phelan A, O'Donoghue $L$, Saunders $K$, et al. Primary school vision screening involving teachers in Nampula, Mozambique. Boston: American Academy of Optometry Annual Conference; 2011 [cited 2014 Aug 20]. Available from: http:// arrow.dit.ie/cgi/viewcontent. cgi?article=1011\&context=scschphycon

16. Department of Basic Education. A message to educators on visual problems amongst learners. c2012 [cited 2014 June 06]. Available from: http://www.education.gov.za/ LinkClick.aspx?fileticket=3jwNMHXj0I0\%3d\&tabid=870\& $\mathrm{mid}=2453$

17. Moher D, Hopewell S, Schulz KF, et al. CONSORT explanation and elaboration: Updated guidelines for reporting parallel group randomised trials. c2010 [cited 2015 Jan 20]. Available from: http://www.consort-statement.org/Media/Default/ Downloads/CONSORT\%202010\%20Explanation\%20and\%20Elaboration\%20 \%28BMJ\%29.pdf

18. Katzenellenbogen J, Abool Karim S. Epidemiology: A research manual for South Africa. Cape Town: Oxford University Press; 2010. 